\title{
Reflexões sobre a relação de crianças surdas com um recurso digital para a apropriação de língua portuguesa escrita em ambiente escolar
}

\section{Reflections on the relationship of deaf children with a digital resource for the appropriation of Portuguese written in a school environment}

Heloísa Andreia de Matos Lins*

Janaina Cabello*

\section{Resumo}

A partir de pesquisa anterior sobre a criação de um recurso digital para ensino-aprendizagem de língua portuguesa escrita como segunda língua (L2), o presente artigo busca evidenciar a importância de considerarmos as percepções das crianças (particularmente as surdas, neste caso) para a elaboração conjunta desses materiais. São apresentados alguns registros das interações, em sala de aula, de um grupo de crianças surdas - meninas entre 7 e 11 anos de idade - com o artefato digital desenvolvido, em que se destacam as formas de audiência infantil na relação com o docente surdo e a mídia em questão. Tendo como aportes teóricos a Pedagogia da Infância e os estudos no campo da Filosofia da Diferença, conclui-se que o espaço escolar tem se configurado como local em que tanto o desenvolvimento de recursos didáticos na educação bilíngue de crianças surdas como as práticas pedagógicas nesse sentido são ainda amplamente controlados pelos adultos. Nesse sentido, considera-se a necessidade de tensionar práticas tradicionais de ensino de língua portuguesa como $L 2$ para crianças surdas, uma vez que há possibilidades para fazeres pedagógicos menos normativos na educação bilíngue, a partir do envolvimento das crianças neste processo e de um outro olhar dos pesquisadores e produtores de recursos midiático-tecnológicos nesse ínterim.

Palavras-chave: Infância. Língua portuguesa como L2. Surdez. Tecnologias.

Recebido em 07/08/2018 - Aprovado em 31/01/2019

http://dx.doi.org/10.5335/rep.v26i2.8473

Doutora em Educação pela Faculdade de Educação da Universidade Estadual de Campinas. Professora do Programa de Pós-Graduação na Faculdade de Educação da Universidade Estadual de Campinas - Linhas Linguagem e Arte em Educação e Educação e Ciências Sociais, Brasil. E-mail: hmlins@unicamp.br

** Mestra e doutoranda em Educação pela Faculdade de Educação da Universidade Estadual de Campinas, na linha de pesquisa Linguagem e Arte em Educação. Professora do Departamento de Psicologia da Universidade Federal de São Carlos, Brasil. E-mail: janainacabello@ufscar.br 


\title{
Abstract
}

\begin{abstract}
Based on a previous research on the creation of a digital resource for teaching and learning Portuguese as L2, the present article seeks to highlight the importance of considering children's perceptions (particularly the deaf ones, in this case) for the joint elaboration of these materials. Some records of the classroom interactions of a group of deaf children - girls between 7 and 11 years of age - are presented with the digital artifact developed, highlighting the forms of children's agency in the relationship with the teacher deaf and the media in question. Having as theoretical contributions the Pedagogy of Childhood and studies in the field of Philosophy of Difference, it is concluded that the school space has been configured as a place where both the development of didactic resources in the bilingual education of deaf children, such as pedagogical practices in this sense, are still largely controlled by adults. In this sense, it is considered the need to stress traditional Portuguese language teaching practices as L2 for deaf children, since there are possibilities for less normative pedagogical activities in bilingual education, from the involvement of children in this process and from another researchers and producers of media-technological resources in the meantime.
\end{abstract}

Keywords: Childhood. Portuguese Language as L2. Deafness. Technologies.

\section{Um contexto sobre a criação de um recurso digital para ensino-aprendizagem de crianças surdas e a interlocução com os estudos da infância}

No ano de 2011, houve a criação do Grupo de Estudos Surdos e Novas Tecnologias (Gestec), ${ }^{1}$ vinculado ao grupo de pesquisa ALLE (Alfabetização, Leitura e Escrita), da Faculdade de Educação da Universidade Estadual de Campinas, em que os processos de alfabetização e letramento (também digitais) na surdez eram temas centrais na discussão de alguns pesquisadores, professores, estudantes de pós-graduação, graduação e outros interessados na temática. A partir disso, algumas pesquisas se voltaram para o desenvolvimento de atividades para um possível aprimoramento das práticas pedagógicas nas escolas de educação básica, tendo como cenário a perspectiva bilíngue na educação de surdos, que tem como pressuposto "[...] que o surdo [...] deve adquirir como língua materna a língua de sinais, considerada a língua natural dos surdos e, como segunda língua, a língua oficial de seu país" (GOLDFELD, 2001, p. 42).

Algumas dessas atividades desenvolvidas foram concebidas como artefatos digitais, ou seja, recursos criados com o objetivo de serem materiais didático-pedagógicos desenvolvidos em suportes digitais e que abarcam possibilidades de contemplar diferentes linguagens (ou semioses) em seu desenvolvimento, além da escrita, tais como imagens, vídeos, cores, áudio, por exemplo. Nas palavras de Rojo (2012, p. 19), recursos que "[...] impregnam e fazem significar os textos contemporâneos quase tanto ou mais que os escritos em letra". 
Portanto, através da utilização de recursos digitais e do uso das novas mídias e tecnologias disponíveis livremente, o Gestec procurava elaborar artefatos digitais para facilitar processos de alfabetização e letramento de crianças surdas, principalmente, e também ouvintes, em início do processo de escolarização, garantindo, para tal, “[...] a presença do 'tripé' Língua Portuguesa em sua modalidade escrita, Libras - a Língua Brasileira de Sinais - (sinais) e Imagem (referentes ao significado das palavras/sinais)" (LINS, CABELLO, 2013, p. 86-87), na tentativa de promover às crianças surdas o acesso à Libras e à língua portuguesa escrita, de modo que elas possam perceber a função social de cada uma, bem como suas diferenças.

A presença desta tríade de semioses (escrita - sinal em Libras - imagem) é condição primordial em uma educação fundamentada nos pressupostos do bilinguismo para os surdos, uma vez que,

[...] se a escrita não repete a história da fala [para crianças surdas] e se é necessário que a criança se desligue do aspecto sensorial dos sons da fala para a construção desse sistema, o aluno surdo terá na língua de sinais a grande possibilidade para desempenhar essa tarefa sem contar necessariamente com a intermediação da fala [oral] (GESUELI, 2003, p. 150).

Em se tratando das potencialidades trazidas pelas mídias digitais, principalmente recursos como imagens e vídeos, a língua de sinais pode ser aliada aos demais recursos semióticos que privilegiam as potencialidades visuais na produção de materiais bilíngues, como aponta Lebedeff (2014, p. 1074):

Para dar conta das especificidades da Libras, tais como os canais de produção e recepção serem diferentes dos das línguas orais e o respeito pela característica visual da língua de sinais, acredita-se que os vídeos são excelentes recursos didáticos, para serem utilizados tanto na modalidade presencial como na modalidade a distância. Entretanto, apenas vídeos de elementos lexicais, que reproduzem a experiência das antigas cartilhas impressas, as quais apresentavam o desenho do sinal com seu significado, não possibilitariam a imersão em práticas sociais de linguagem.

Atentando-nos a essa ressalva feita por Lebedeff, naquele período, observávamos a expressiva falta desses recursos digitais que, de fato, priorizassem a Libras e uma pedagogia bilíngue/bicultural e visual, que:

[...] deve basear-se numa ampla visão sócio-antropológica [sic] segundo a qual o surdo é um indivíduo com características diferentes da maioria, [...] e que, historicamente, como tantas outras minorias, tem sido impedido de exercer seus direitos sociais - principalmente o de usar uma língua diferente e de ser educado na sua língua natural (SÁ, 1997, p. 17). 
Ponderando que “[...] qualquer ação pedagógica [para o ensino de surdos] precisa considerar sua condição linguística e oferecer a Libras (Língua Brasileira de Sinais) como forma de acesso" (LACERDA; ALBRES; DRAGO, 2013, p. 67), partíamos do pressuposto de que:

[...] os meios disponibilizados pelas novas tecnologias carregam consigo possibilidades importantes de construção de ferramentas pedagógicas para o ensino da língua portuguesa, em sua modalidade escrita, para crianças surdas, através, por exemplo, da criação de objetos de aprendizagem (OAs), "compreendidos como qualquer entidade digital (vídeo, sites, softwares, simulações, aplicativos etc.) que possa ser usada e reutilizada com fins pedagógicos" (ARAÚJO, 2011 apud LINS; CABELLO, 2013, p. 86).

Deste modo, para além das possibilidades ofertadas pelas tecnologias digitais, cabe destacar também a importância do protagonismo surdo nessas práticas, para que seja possível constituir um "currículo surdo", como defendido também pela pesquisadora surda Karin Strobel (2018, p. 92, grifos nossos ${ }^{2}$ ), quando afirma que esses artefatos "[...] não devem ser considerados apenas como entretenimento, mas sim um importante espaço educacional que faz formar a pedagogia surda e o currículo surdo e que colaboram na constituição de identidades culturais positivas de sujeitos surdos".

É nesse contexto que, no ano de 2013, uma pesquisa mais ampla, realizada por Cabello (2015, p. 13), teve início, com o objetivo de realizar:

[...] uma análise contrastiva da criação e desenvolvimento de um Objeto de Aprendizagem (OA) e dos usos e impressões de participantes Surdos (um professor e algumas crianças em processo de alfabetização), a partir do contato com o artefato digital e das relações estabelecidas no/pelo processo de ensino-aprendizagem de língua portuguesa escrita como segunda língua. ${ }^{3}$

O trabalho apresenta uma discussão mais adensada sobre as potencialidades do desenvolvimento de recursos digitais como materiais de apoio aos professores alfabetizadores de crianças surdas, em uma perspectiva bilíngue de educação de surdos, que considera a Libras como primeira língua (L1), ou seja, como a forma com a qual a criança se expressa em uma língua que "[...] possibilita ao sujeito surdo reconhecer-se e projetar-se no mundo [narrando-se] pela linguagem e determina-se assim, a língua de sinais como parte subjetiva e constitutiva da criança surda" (MARTINS; LACERDA, 2016, p. 168), como já apontado.

Naquele momento, questões relacionadas às consequências da leitura e da escrita realizadas em suportes digitais também foram problematizadas, considerando que as tecnologias digitais podem fazer com que a alfabetização se aproxime 
também de um tipo de alfabetização audiovisual (FRADE, 2007), ou seja, percebe-se o surgimento de novas pedagogias, que podem se aproximar de diversos recursos multimídias, apoiando de maneira contundente as crianças surdas quanto à apropriação da escrita.

Daquele período para cá, portanto, enveredamo-nos como pesquisadores também na questão das multissemioses/multimodalidades para o aprendizado da língua portuguesa escrita (CABELLO, 2015; LINS, 2017), uma vez que tais conceitos, quando pensados na articulação com as tecnologias digitais, materializam-se nas diferentes formas de linguagem - escrita, oral, visual, por exemplo - em interação. De acordo com Rojo e Moura (2012, p. 19), portanto, entendemos que, diante dos recursos digitais, são outras as habilidades para que possamos atribuir significado aos textos multimodais e multissemióticos que circulam, sobretudo, na esfera digital: “[...] textos compostos de muitas linguagens (ou modos, ou semioses) e que exigem capacidades práticas de compreensão de produção de cada uma delas (multiletramentos) para fazer significar”.

Assim, para além de refletir sobre o protagonismo surdo em relação ao desenvolvimento de artefatos digitais bilíngues, debruçamo-nos também sobre o protagonismo infantil nesses processos, aprofundando as discussões em torno dos estudos interdisciplinares da infância, especificamente sobre as relações de crianças e adolescentes com as diferentes mídias que habitam suas experiências cotidianas.

Tal como propõe Buckingham (2007, 2008), nessa área de desenvolvimento midiático endereçado ao público infanto-juvenil, é fundamental a escuta atenta às perspectivas das crianças e dos jovens, bem como de sua participação ativa nos processos de criação e também nas pesquisas, uma vez que há muitos elementos completamente ignorados pelos adultos nesse âmbito.

No entanto, ainda que os adultos desconheçam muitos aspectos que poderiam contribuir para a compreensão da forte relação entre crianças-jovens/mídias, é importante considerar as questões geracionais (portanto, relações de poder-saber) em jogo, tal como Sarmento (2005) nos chama a atenção, ao discutir o conceito de administração simbólica da infância, que se refere aos "[...] modos paternalistas de organização social e de regulação dos cotidianos, o desapossamento de modos de intervenção e a desqualificação da voz das crianças na configuração dos seus mundos de vida e a colonização adultocentrada dos modos de expressão e de pensamento das crianças" (SARMENTO, 2005, p. 369-370), na direção do que Foucault tratou sobre os processos de disciplinação da infância (FOUCAULT, 2000). 
Sarmento também destaca, nesses contextos, a ideia de negatividade constituinte da infância, instaurada na modernidade, ou seja, a norma da infância (que vem sofrendo mudanças, certamente):

[...] a criança não trabalha, não tem acesso directo ao mercado, não se casa não vota nem é eleita, não toma decisões relevantes, não é punível por crimes (é inimputável). Essa norma assenta num conjunto estruturado de instituições, regras e prescrições que se encarregam da "educação" da criança, especialmente a escola e a família (SARMENTO, 2006 apud DELGADO; MULLER, 2006, p. 17-18, grifos nossos).

Assim, numa outra perspectiva, para a compreensão da participação dessas crianças - tanto na pesquisa inicial, de Cabello (2015), como mais recentemente, para refletir sobre a relação delas com a mídia produzida -, centramos nossas concepções a partir das contribuições da chamada Pedagogia da Infância, que é também compreendida

[...] a partir do reconhecimento do nascimento de uma área, ou subárea da Educação, que se vinha preocupando com instâncias educativas específicas, diferentes e anteriores à escola, mas não só. A acumulação destes estudos também apresentava uma marca peculiar, ao tomar como objeto de preocupação a infância e os processos educativos voltados para ela, de forma diferente daquelas tradicionalmente consolidadas nas teorias educacionais, ou seja, contestando criticamente as Pedagogias da criança, cimentadas nas teorias educacionais liberais do século XX (ROCHA; LESSA; BUSS-SIMAO, 2016, p. 34).

Nesse outro contexto, para a compreensão e o fortalecimento das agências infantis (a positividade da infância, portanto), algumas áreas do conhecimento tiveram um papel preponderante, tal como a sociologia da infância, uma das áreas constituintes da Pedagogia da Infância.

Assim, buscando aprofundar as discussões em torno dos estudos interdisciplinares da infância, especificamente sobre as relações de crianças e adolescentes com as diferentes mídias que habitam suas experiências cotidianas, e compreendendo que as crianças constituem um importante grupo social como atores/(re)produtores de saberes na sociedade de consumo globalizada, este trabalho também procura refletir sobre a questão das diferenças nesses contextos, de maneira mais ampla, assim como sobre as subjetividades infantis nesses processos (de crianças ouvintes e surdas), em que a escola ocupa um lugar de destaque.

No entrelaçamento dos campos de estudo da pedagogia bilíngue, educação de surdos e da Pedagogia da Infância, foram desenvolvidas, inicialmente, atividades denominadas de sequências didáticas, que pretendiam atender às necessidades de um grupo de crianças surdas, principalmente, no que se refere ao processo de aprendizagem do português escrito como segunda língua (L2). Ao final do processo 
de desenvolvimento e diante da interação do professor surdo e das crianças surdas com o material, Cabello (2015, p. 133) explicita que outros caminhos podem ser percorridos a partir do desdobramento da pesquisa, destacando a necessidade de que, "[...] para que esses recursos possam ser mais efetivos e significativos, é imprescindível o envolvimento dos sujeitos Surdos no planejamento da arquitetura desses artefatos, apontando para um cenário de pesquisa que poderia ser mais explorado nessa direção".

Diante do exposto, assumindo as perspectivas fluidas e instáveis da produção de conhecimentos, nos tempos atuais, e apoiadas por alguns referenciais dos estudos pós-estruturalistas (ou pós-modernos) - aqui principalmente deleuzianos -, voltamo-nos aos dados produzidos pela pesquisa de Cabello (2015), sob a influência dessas outras contribuições teóricas, destacando a participação de algumas crianças na relação com um professor também surdo, diante do recurso digital produzido, para fins de apropriação da língua portuguesa.

A intenção principal deste outro foco aqui esboçado foi a de destacar as lacunas quanto ao processo participativo das crianças surdas, desde o início da criação e da arquitetura pedagógicas (digitais, neste caso). Isso significa prescindir (ainda mais) das crianças como protagonistas nas pesquisas e na criação de mídias/recursos digitais de aprendizagem. Como argumenta Cabello (2015, p. 34), sobre "[...] a essencialidade da criança como participante da pesquisa [...]", buscamos destacar o caráter fundante dessa participação, desde a concepção inicial do projeto de criação midiática/tecnológica.

Para o deslocamento de nossos próprios olhares, a criação de outros mapas, de outros fluxos e agenciamentos, tal como configurados por Deleuze (1997), foi fundamental atentar para a fluidez da experiência cartográfica (ou de pesquisa) e desejar, obviamente, percorrer outras vias, desprendendo-se de caminhos fixos e anteriormente determinados:

Os mapas, ao contrário, se superpõem de tal maneira que cada um encontra no seguinte um remanejamento, em vez de encontrar nos precedentes uma origem: de um mapa a outro, não se trata da busca de uma origem, mas de uma avaliação dos deslocamentos. Cada mapa é uma redistribuição de impasses e aberturas, de limiares e clausuras, que necessariamente vai de baixo para cima. Não é só uma inversão de sentido, mas uma diferença de natureza [...] cujos objetos, mais do que permaneceram afundados na terra, levantam vôo [...] Os mapas não devem ser compreendidos só em extensão, em relação a um espaço constituído por trajetos. Existem também mapas de intensidade, de densidade, que dizem respeito ao que preenche o espaço, ao que subtende o trajeto [...] (DELEUZE, 1997, p. 75-76, grifos do autor). 
Assim, concebemos uma pluralidade de trajetos que seriam legíveis e coexistentes num mapa, mas que muda de sentido "segundo aqueles que são retidos" (DELEUZE, 1997, p. 79). Desse modo, uma outra rota foi trilhada, outros sentidos foram almejados (devires também nossos, de pesquisadoras, no atravessamento com as cenas das crianças que descreveremos a seguir) e tecidos na busca do que as crianças surdas poderiam nos dizer, porque nessa complexa simplicidade do que nos (re)apresentam: "À sua maneira, a arte diz o que dizem as crianças. Ela é feita de trajetos e devires, por isso faz mapas, extensivos e intensivos" (DELEUZE, 1997, p. 78).

Valeria a pena, portanto, lançarmo-nos em outros fluxos trazidos e em novas rotas traçadas pelas crianças, uma vez que há possibilidades para fazeres pedagógicos menos normativos na educação bilíngue, a partir do envolvimento das crianças neste processo e de um outro olhar dos pesquisadores e produtores de recursos midiático-tecnológicos nesse cenário.

\section{(Re)tomando as contribuições infantis diante do recurso digital: alguns fluxos e deslocamentos}

Cena 1 - Crianças utilizando o recurso digital "O Astronauta"

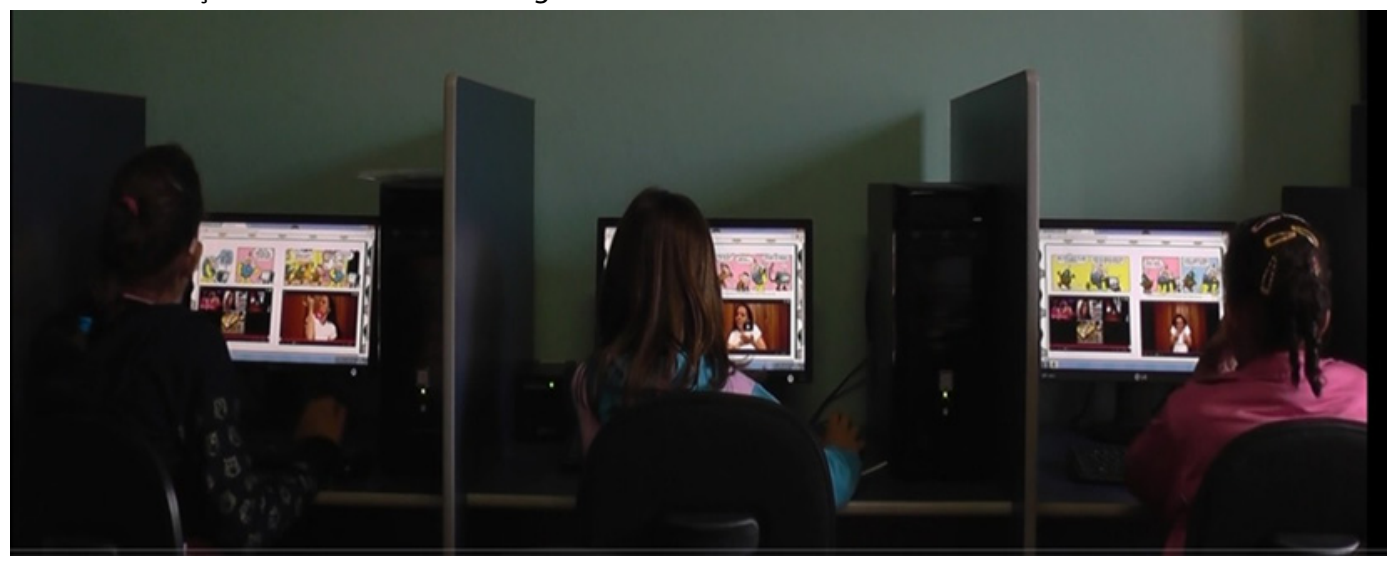

Fonte: Cabello (2015).

O professor pede para trocarem de lugar, cada uma indo explicar a história da outra, lendo o que cada personagem poderia ter dito na história da outra. Elas recontam, leem os balões e o que não lembram, buscam olhar os diálogos que montaram em suas próprias histórias e, a partir daí, dizem o que está escrito nos balões. Ao término da aula, o professor veio dizer que pediu para elas recontarem as histórias uma da outra porque assim poderia perceber se estão conseguindo ler, se apenas decoraram a posição dos balões ou se apenas lembram do significado das palavras pela cor do balão: "consigo ver se é a leitura ou a memória visual do desenho" - justificou. 
Cena 2 - Destaque da interação de uma das crianças com o material apresentado
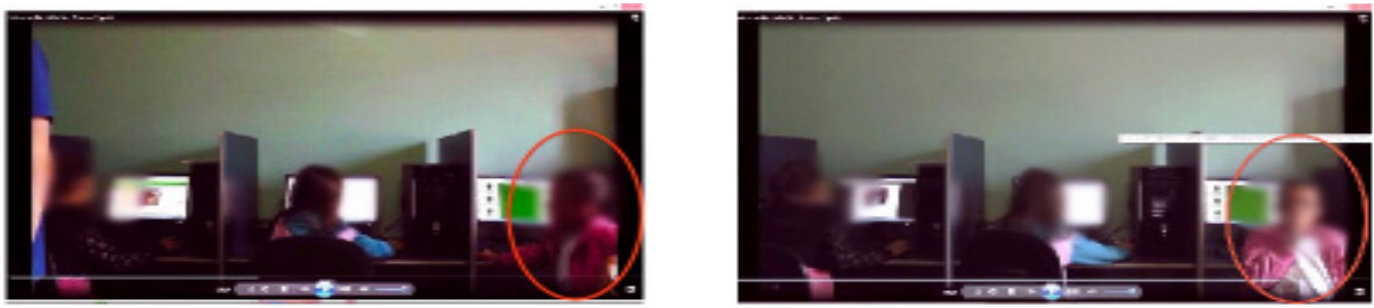

Ela olha o que Alice está fazendo e grita ao seu lado, fazendo o sinal de "NOME". Como Alice não entende o que ela quer dizer, ela se aborrece e senta novamente. Valéria chama outra criança para ir lá com ela, começa a conversar de outras coisas. Novamente olha o que Alice está fazendo, mas não tenta imitar ou mexer novamente em seu computador (notas do caderno de campo da pesquisadora).

Fonte: Cabello (2015).

Cena 3 - Considerações da pesquisadora a partir das observações das interações estabelecidas entre professor, crianças e recurso digital durante a aula

Mesmo quando é possível com que as crianças estabeleçam relações mais autônomas com o material, aguardam por orientações do professor do que deve ser feito, ou seja, embora já tenham se apropriado das tecnologias em outros contextos não-escolarizados, a situação de ensino-aprendizagem tradicional (sala de aula, professor que "instrui" e alunos que "seguem as instruções") parece estar também bastante arraigada nos modos de fazer dos alunos.

Fonte: Cabello (2015).

As cenas supracitadas foram selecionadas do estudo realizado por Cabello (2015), por trazerem possibilidades de reflexão quanto ao próprio material desenvolvido, uma vez que tal processo foi elaborado por nós, pesquisadoras adultas e ouvintes, e contou com a participação das crianças num momento posterior à sua criação (projeto piloto), fosse por condições concretas da execução do estudo, como as dificuldades técnicas já apresentadas na referida pesquisa (como softwares livres que não comportavam vídeos, o que seria fundamental numa arquitetura que privilegiasse Libras; tempo para execução do recurso/aplicativo; entre outras), fosse pela compreensão de que a participação das crianças não seria possível desde o início, muito pela percepção de que alguns elementos do recurso/aplicativo, numa perspectiva bilíngue/bicultural/visual, precisariam ser executados por estudiosos (adultos) da área. Assim, ainda que concebêssemos como importante a participação de surdos nesse processo (crianças e professor), uma concepção adultocêntrica permaneceu praticamente "intocada" no estudo, deixando para um outro momento 
a participação das crianças surdas (após a criação do OA, já no momento dos usos e percepções a partir daí).

Contudo, buscamos romper com uma série de questões epistemológicas, desde o início de seus estudos na área, como: a) com a concepção das próprias tecnologias no campo do bilinguismo e/ou da educação especial, as chamadas tecnologias assistivas (CAMPOS, 2015), que foram assumidas como tecnologias simplesmente; b) com uma concepção salvacionista diante das mídias/tecnologias no ensino, em contrapartida, buscamos compreender as tecnologias/mídias como (re)produção/ (re)apropriação cultural; c) com as práticas tradicionais no ensino de língua portuguesa como L2 para crianças surdas, por meio das possibilidades para fazeres pedagógicos menos normativos na educação bilíngue, a partir do envolvimento das crianças neste processo; d) com a utilização de materiais prontos e desenvolvidos por grandes corporações (lógica de mercado e as questões de audiência ativa x passiva ${ }^{4}$, quando optamos pela utilização de softwares livres e criados com ajuda de crianças e docentes; e, não menos importante, e) com concepções de leitura e escrita hegemônicas, em direção a concepções multimodais/multissemióticas/híbridas.

De qualquer modo, não se garantiu, naquele momento, uma reflexão mais aprofundada sobre a referida perspectiva adultocêntrica nesses processos, para que se considerasse que crianças e adolescentes (re)produzem as mídias/tecnologias - as chamadas agências infantis (BUCKINGHAM, 2007) -, e tal processo (re) produtivo deveria ser central na concepção de educadores/pesquisadores, desde o início do processo participativo (desde a concepção do OA, portanto), porque tal aspecto poderia aproximar/afastar tais crianças e adolescentes do conteúdo projetado e, consequentemente, das atividades pedagógicas mais estritas sobre Libras e língua portuguesa.

Houve uma maior preocupação com a construção de uma arquitetura/formato digital que atraísse o interesse desses participantes, por meio da criação de atividades-jogo, o que (em si) não garantiu tal envolvimento, como será discutido a seguir. 


\section{(Re)Pensando os fazeres na pesquisa com crianças surdas: o que elas têm a nos dizer?}

Relato 1 - Nem todas as crianças têm o desejo de interagir com o recurso digital

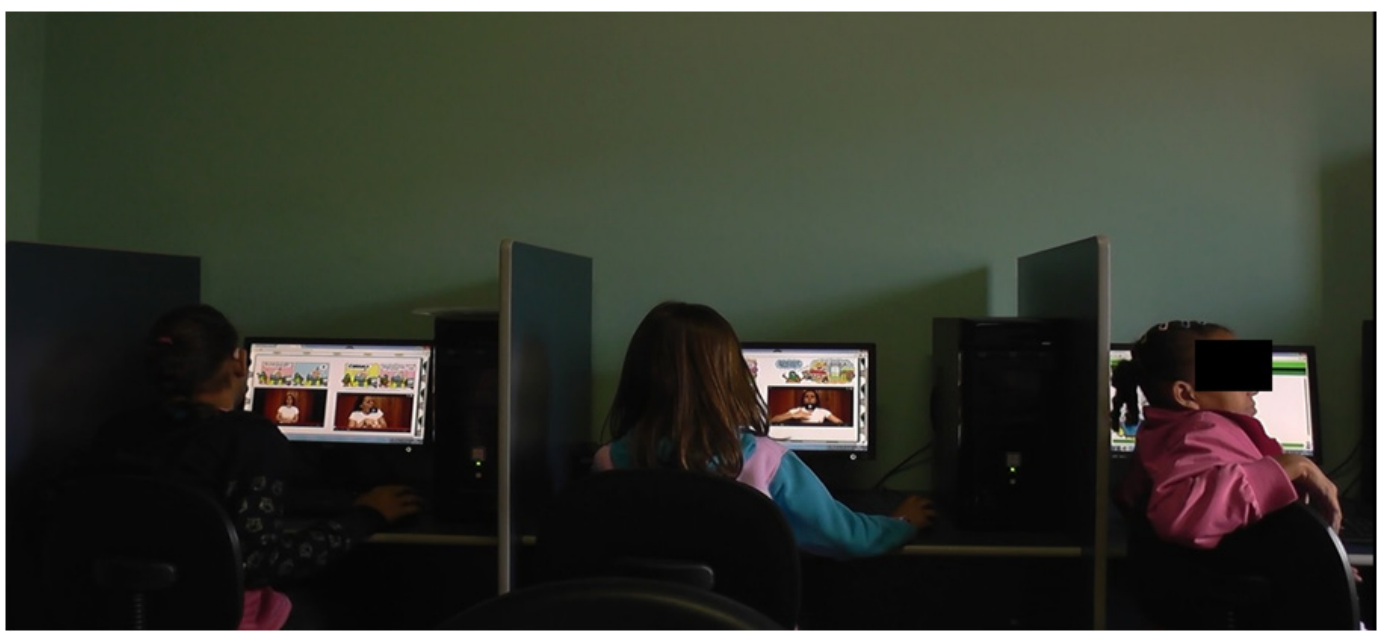

Fonte: Cabello (2015).

Relato 2 - Excerto do diário de campo com o registro de um dos momentos de interação das crianças com o recurso digital

Valéria repete para mim a instrução que acabou de receber do professor e faz uma cara aborrecida, se mexendo na cadeira. Valéria fica de costas para o computador, mexendo no cabelo, debruçada sobre o encosto da cadeira. Depois volta a olhar para sua tela e depois para o que as outras crianças estão fazendo. Continua sentada meio de lado, meio de costas para o computador, olhando para o professor, para o lado, para a janela. Deita na cadeira de costas para o computador.

Fonte: Cabello (2015). 
Relato 3 - Momento da interação das crianças com o artefato digital

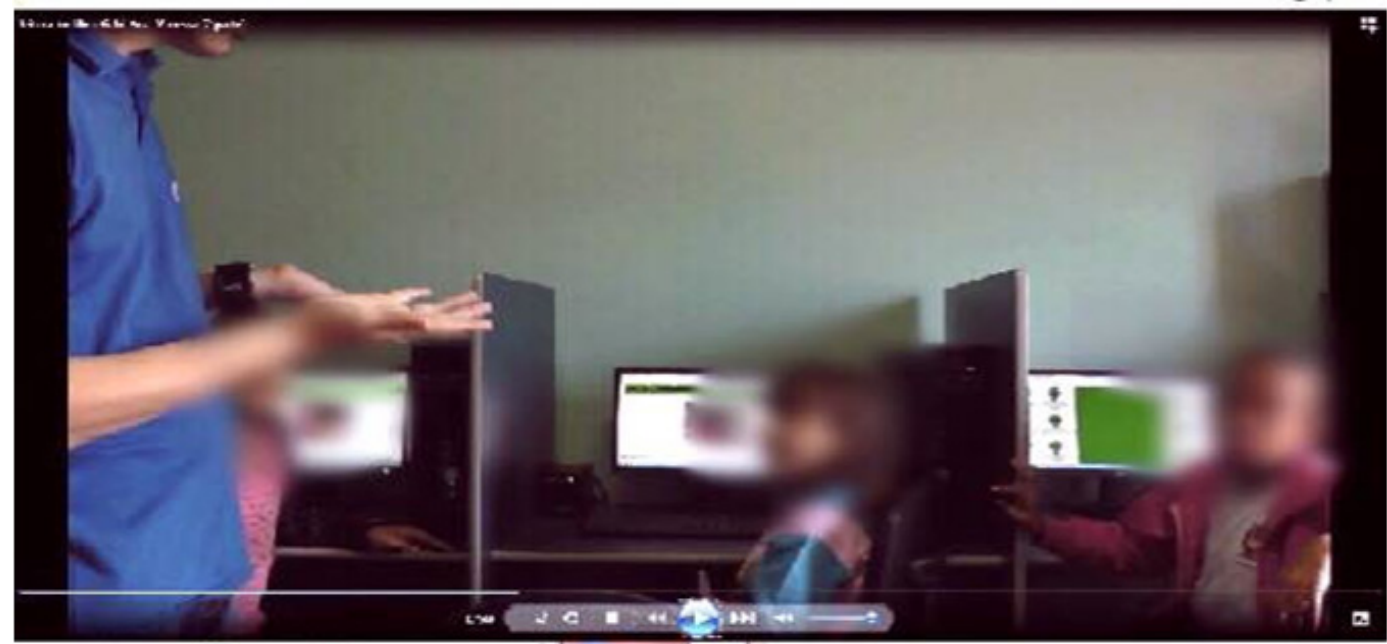

Todas as crianças tiveram dificuldades para iniciar a interação com o OA espontaneamente. Ficaram aguardando as orientações do professor para saber como começar, como fazer, o quê deveria ser feito. [...] somente clica na imagem quando ele [professor] diz para ela clicar, daí percebe que a imagem contém também um vídeo em Libras. Quando o vídeo acaba, pergunta ao professor 'que faz agora que parou?' [...] ela pergunta como faz para começar e ele diz que para virar a página precisa ir com o cursor do lado direito. Ela pergunta: aqui? (notas do caderno de campo da pesquisadora, ,2015).

Fonte: Cabello (2015).

Relato 4 - Momento da interação das crianças e da mediação do professor na interação com o artefato digital

Em seguida, chama o professor e repete "acabou, acabou". O professor diz "acabou tudo? Olha lá, tem mais" e se vira para outra criança. Alice tenta chamar o professor e aguarda sentada, olhando para Valéria. O professor retorna e ao verem que a história acabou, o professor diz "agora você vai ver o dicionário. Como você vai ver o dicionário? Volta de novo aqui" - e aponta onde a criança deve clicar. Ela fica em dúvida e ele aponta novamente, "clica você vai ver uma mão" e ela repete o sinal de "mão". Gisele a ajuda, mostra onde tem que clicar. Alice clica e abre o vídeo explicando o que é o dicionário.

Fonte: Cabello (2015).

As interações das crianças com o artefato digital evidenciaram que, embora o material desenvolvido tivesse como um dos objetivos atender as necessidades 
das crianças surdas, no que se refere a seus desejos e interesses, o recurso não se fez atrativo ou interessante em muitos momentos, como exemplificado a partir dos excertos supracitados. É importante ressalvar que assumimos, com Deleuze e Guattari (2011, p. 44), os desejos não como falta, mas como produção: "A falta é um contraefeito do desejo, depositada, arrumada, vacuolizada no real natural e social. O desejo está sempre próximo das condições de existência objetiva, une-se a elas, segue-as, não lhes sobrevive, desloca-se com elas, [...]”.

Nessa direção, embora tenhamos buscado elaborar atividades consideradas lúdicas e interessantes ao grupo de crianças (a partir do conhecimento das línguas envolvidas ou da faixa etária, por exemplo), a interação entre as crianças e o material bilíngue desenvolvido nem sempre se mostrou espontânea ou mesmo prazerosa, evidenciando que as nossas expectativas, de pesquisadoras adultas (e ouvintes), ao desenvolver o material, eram bastante diferentes das expectativas e da compreensão das crianças, a partir de suas experiências e interações com as mídias e tecnologias, em seus contextos cotidianos e de aprendizagem (de suas culturas lúdicas também, como será discutido a seguir).

Nesse sentido, em diversos momentos, as manifestações das crianças, feitas por intermédio de seus corpos, de suas expressões faciais, de seus olhares (como exemplificado na imagem do Relato 1 , disseram a respeito de como as crianças não são consumidoras passivas de recursos didáticos digitais - como não são de quaisquer outras mídias. Os modos como as crianças interagiram (ou deixaram de interagir) com o artefato evidenciam modos de resistências/agências infantis (BUCKINGHAM, 2007), em que as crianças inventam e reinventam suas brincadeiras e seus modos próprios de aprendizagem, o que se configuraria nas culturas infantis, no dizer de Corsaro (2011).

Sobre essa relação das crianças com os recursos digitais, com Brougère (2010), poderíamos refletir sobre o grau de potência criado para a chamada cultura lúdica, pois ela está bastante orientada para a manipulação de objetos. Da mesma forma, o autor salienta que, como consequência dessa manipulação constituinte da cultura lúdica, esta última se desenvolve sob o impulso de novos brinquedos:

Novas manipulações (inclusive jogos eletrônicos e de videogame), novas estruturas de brincadeiras, ou desenvolvimento de algumas em detrimento de outras, novas representações: o brinquedo contribui para o desenvolvimento da cultura lúdica. Porém, o brinquedo se insere na brincadeira através de uma apropriação, ou seja, deixa-se envolver pela cultura lúdica disponível, usando práticas de brincadeiras anteriores (BROUGÈRE, 2010, p. 54). 
Assim, é importante atentarmos para o fato de que, nessa manipulação realizada pelas crianças, há manifestações de tentativas de (re)apropriação do que foi projetado por adultos ouvintes e também para uma lógica ainda marcadamente “pedagógica”, ou seja, neste caso, no experienciado em aula e para o ensino de uma língua, por mais que se buscasse romper com essa perspectiva "pedagogizante", por meio da arquitetura desenvolvida em forma de livro digital, com jogos e outras atividades, por exemplo. Instala-se nessa relação, portanto, a tentativa de compreensão, por parte das crianças, do que estava em jogo, de fato, a começar pelo próprio personagem central escolhido por adultos ouvintes: o Astronauta, da turma da Mônica. Essas crianças tinham contato com esse personagem? De que forma? Como lidaram com essa aproximação, inicialmente, a partir dos referenciais circunscritos nessas culturas infantis? Enfim, essas são algumas das questões que não puderam ser exploradas naquele momento, mas seriam cruciais numa tentativa de compreensão do papel desses objetos numa lógica escolar (e também fora dela, ainda que as questões, certamente, fossem outras ${ }^{5}$ ).

Ainda, é importante destacar que, nos momentos em que as crianças se fizeram protagonistas, muitas vezes, o próprio lugar do adulto foi colocado em jogo. No Relato 4, fica evidente o trabalho coletivo infantil, em que as crianças constroem seus modos de aprendizagem, com a intervenção do professor sendo colocada em segundo plano, após as crianças assumirem a colaboração (umas das outras) para a aprendizagem.

Nesse sentido, compreendemos que as crianças, com seu "olhar estrangeiro", ou seja, de fora de uma lógica adultocêntrica de aprendizagem, conseguem encontrar novos percursos para a construção de seus saberes, menos instituídos, adotando outras percepções não previstas pelos adultos. Nessa ação de aparente desordem e (re)apropriação, subvertem o que foi proposto por um desenho pedagógico inicial do recurso digital, trazendo outros percursos, fragmentando um caminho linear, pré-concebido pelos adultos, materializado pelo desenho (arquitetura) pedagógico.

Quando resistem ao que é proposto pelos adultos inseridos (também) em contextos de fazeres escolarizados, as crianças provocam uma ruptura, um dissenso, que, nas palavras de Oliveira (2015, p. 449), causam uma “[...] perturbação no sensível, esse marulho, um rumor que produz uma modificação singular do que visível, dizível, contável".

Como argumentado por Buckingham (2007 apud CABELLO; LINS, 2017, p. 187): “As crianças não são vistas aqui como receptores passivos das mensagens da mídia, mas como processadores ativos de significados. [...]. Nessa pers- 
pectiva, o significado dos textos midiáticos não é apenas entregue ao público, mas construído por ele".

As crianças, em sua lógica, mostraram-se atentas para a descoberta de outras ideias, além das delineadas pelos adultos, atribuindo novos contornos aos caminhos para a interação com o recurso digital. Subverteram (abandonaram?6), desse modo, um território proposto para o processo de apropriação da escrita, apresentado pelo objeto de aprendizagem (e pelos fazeres escolarizados, de modo mais amplo), desterritorializando/reterritorializando talvez, escapando através da invenção de linhas de fuga para a construção do novo - um novo território. Nas palavras de Deleuze e Guattari (2009, p. 69): “Temos que pensar a desterritorialização como uma potência perfeitamente positiva, que possui seus graus e seus limiares e que sempre é relativa, tendo, em reverso, uma complementaridade na reterritorialização".

Nesse possível acontecimento da (des)territorialização/reterritorialização, ao que parece, nem tudo foi passível de brincadeira e encantamento por parte das crianças $^{7}$, ou de articulação com suas culturas/repertórios anteriormente desenvolvidos. A própria relação das crianças com o objeto digital (como brinquedo, ou não, como se vê na citação a seguir), também pode ser refletida, pois, segundo Brougère (2010), para gerar brincadeiras, é preciso que os conteúdos ou imagens (da televisão, dos jogos, etc.)

[...] possam ser integradas ao universo lúdico das crianças, às estruturas que constituem a base dessa cultura lúdica mencionada '...]. É preciso que tais conteúdos possam ser integrados nas lógicas da brincadeira, que variam menos do que as representações [...]. Nem tudo se presta à brincadeira. A brincadeira não aparece como uma imitação servil [...], mas sim como um conjunto de imagens que têm a vantagem de ser conhecidas por todas, ou quase todas as crianças, de ser combinadas, utilizadas, transformadas, no âmbito de uma estrutura lúdica. Isso ilustra bem a dupla dimensão da brincadeira: uma estrutura sobre a qual representações variadas vêm se inserir para animá-la, renová-la. Os efeitos dos modismos, ou do entusiasmo passageiro, atingem mais facilmente esse segundo nível” (BROUGÈRE, 2010, p. 56-57, grifos nossos).

Brougère (2010) ainda destaca que o investimento das crianças na brincadeira está relacionado diretamente ao conhecimento que elas têm dos personagens midiáticos. Segundo o autor, a televisão (neste caso, assumimos a mídia em geral) não se coloca contrariamente às brincadeiras (numa ideia que remeta à passividade das crianças, como espectadoras apenas), mas a alimenta, influencia e estrutura, na medida em que a brincadeira teve uma origem naquilo com o que a criança é confrontada. $\mathrm{O}$ autor ainda salienta que a brincadeira permite a descarga das emoções acumuladas durante a recepção (no caso que trata, a televisiva), a tomada 
de distanciamento, a invenção e criação em torno das imagens recebidas. No entanto, ainda precisamos investigar como tais processos poderiam se dar no âmbito dos jogos digitais propostos para o campo da educação, numa perspectiva de fato (cri)ativa para as crianças. Assim, como tais recursos digitais poderiam se tornar brinquedos, fundamentalmente, e atrair a atenção e os desejos das crianças? Seria possível criar uma situação delirante dos recursos, novos fluxos (a partir das crianças), em territórios escolares/pedagógicos?

Nessa direção, Deleuze (1997, p. 65) destaca que as "formulações delirantes são como núcleos da arte”, quando argumenta sobre as transgressões criativas necessárias para o encontro com a língua (e da literatura, no caso particular em que analisa na referida obra, mas que talvez pudesse se apresentar numa história em quadrinhos, como foi a proposta do recurso digital aqui discutido, dada a proximidade com muitas crianças). Deleuze (1997) afirma que é preciso fazer a língua gaguejar; um processo criador, portanto, "A cada vez que uma língua é submetida a tais tratamentos criados, é a linguagem inteira que é levada ao seu limite, música ou silêncio [...]. O suspense dos corpos e o balbucio da língua constituem o corpo-linguagem" (DELEUZE, 1997, p. 66).

Assim, para que a língua se tornasse brinquedo, para que gaguejasse, de fato, o recurso digital deveria trazer essa potencialidade não apenas na arquitetura, mas nos tópicos linguísticos, nas escolhas dos personagens, na atenção plena às vozes infantis, para tal e para as intercessões (até desconhecidas) daí decorrentes: fazer a língua e as crianças pegarem delírio. Tarefa não menos complexa para estudos posteriores, mas que provavelmente pode nos indicar tendências de percurso nesse terreno investigativo movediço.

Diante desse contexto, salientamos que, embora haja grande urgência para o desenvolvimento de recursos digitais potentes para o ensino-aprendizagem das crianças (principalmente no caso das crianças surdas, como destacamos, em que as múltiplas semioses e a presença da língua de sinais são centrais), não menos importante é a participação ativa dessas crianças, desde o início, no processo de criação de tais recursos, bem como o acompanhamento das tarefas desenvolvidas pelos adultos nesses processos: o que pensam e o que podem nos ajudar a descobrir nesses novos cenários? Como podem nos apoiar, também, na descoberta de modos outros para a concepção/utilização das mídias e tecnologias na educação, para muito além do que pressupõe a gramática escolar e sua lógica que, via de regra, arrasta o brincar espontâneo das crianças numa obrigação em aprender que faz desmotivar? 


\section{Notas}

1 Disponível em: <https://www.fe.unicamp.br/alle/gestec.htm>.

2 Os termos em destaque não serão debatidos, por não ser esse o objetivo deste trabalho, mas é importante salientar que o movimento surdo (em nível mundial e também nacional) traz contribuições significativas a partir do que apontam como especificidades do ser-surdo, de suas identidades culturais. De qualquer modo, há discussões nesse campo que questionam as forças mobilizadoras, de fato, da construção das resistências a partir das identidades culturais para quaisquer grupos que constituem minorias sociológicas e políticas. Ver mais em Guattari e Rolnik (2013), por exemplo.

3 O trabalho está disponível em: <http://www.ecsoft.com.br/ESP2/ESP2.htm>; e <http:/www.ecsoft.com.br/ ESP3/ESP3.htm>. Questões metodológicas mais detalhadas podem ser encontradas em Cabello (2015).

4 A audiência é concebida a partir das contribuições de Buckingham (2007), quando se refere ao consumo de mídias x participação ativa nos processos de desenvolvimento dessas. Assim, o autor aponta que as audiências não pressupõem maior "atividade” por parte de quem consome mídias prontas. Buckingham (2007, p. 135) destaca que grande parte faz uso "casual e distraído”.

5 Observar, por exemplo, no Relato 3, a dificuldade das crianças em iniciar a interação com o objeto digital apresentado pelo professor. É bastante provável que, em outra situação, não escolar, as crianças ousassem manipular tal recurso, sem maiores cuidados ou sem depender dos "comandos" adultos e professorais. A esse respeito, ver também Lins (2017) e Lins e Ricarte (2017), em que algumas crianças de 4 ou 5 anos usam, em suas casas, com destreza e autonomia, jogos censurados ao público infantil e indicados para maiores de 18 anos.

6 Voltar ao Relato 2, por exemplo, em que Valéria chega a deitar na cadeira de costas para o computador.

7 Cumpre ressaltar que alguns elementos geraram algum interesse das crianças, como a presença dos vídeos em Libras ou a possibilidade de manipularem alguns personagens da história para a construção de cenários diversos (CABELLO, 2015), mas estudos posteriores precisariam atentar para esses aspectos como constituintes do brincar, de fato, ou como apenas um "entusiasmo passageiro", conforme Brougère (2010) analisa em alguns casos.

\section{Referências}

BROUGÈRE, G. Brinquedo e Cultura. São Paulo: Cortez, 2010.

BUCKINGHAM, D. Crescer na era das mídias: após a morte da infância. São Paulo: Loyola, 2007.

. Más allá de la tecnología: aprendizaje infantil en la era de la cultura digital. Buenos Aires: Manantial, 2008.

CABELLO, J. Desenvolvimento de Objetos de Aprendizagem para alfabetização de crianças surdas: novas tecnologias e práticas pedagógicas. 2015. 186 f. Dissertação (Mestrado em Educação) - Faculdade de Educação, Universidade Estadual de Campinas, Campinas, 2015.

CABELLO, J.; LINS, H. A. M. Um olhar para as infâncias, as diferenças e as mídias como entrecruzamento: o que se (re)produz mesmo? In: CABELLO, J.; LINS, H. A. M. (Org.). Mídias, infâncias e diferenças. Campinas: Leitura Crítica, 2017. p. 14-16.

CAMPOS, M. L. I. L. O processo de ensino-aprendizagem de Libras por meio do Moodle da UAB-UFSCar. Tese (Doutorado em Educação Especial) - Programa de Pós-Graduação em Educação Especial, Universidade Federal de São Carlos, São Carlos, 2015.

CORSARO, W. A. Sociologia da infância. Porto Alegre: Artmed, 2011. 
DELEUZE, G. Crítica e clínica. São Paulo: Editora 34, 1997.

DELEUZE, G.; GUATTARI, F. Mil platôs: capitalismo e esquizofrenia. São Paulo: Editora 34, 2009.

DELEUZE, G.; GUATTARI, F. $O$ anti-édipo: capitalismo e esquizofrenia I. São Paulo: Editora $34,2011$.

DELGADO, A. C. C.; MULLER, F. Infâncias, tempos e espaços: um diálogo com Manuel Jacinto Sarmento. Currículo sem Fronteiras, Porto Alegre, v. 6, n. 1, p. 15-24, jan./jun. 2006.

FRADE, I. C. A. S. Alfabetização digital: problematização do conceito e possíveis relações com a pedagogia e com a aprendizagem inicial do sistema de escrita. In: COSCARELLI, C. V.; RIBEIRO, A. E. Letramento digital: aspectos sociais e possibilidades pedagógicas. Belo Horizonte: Autêntica, 2007. p. 29-83.

FOUCAULT, M. Vigiar e punir. Petrópolis: Vozes, 2000.

GESUELI, Z. M. Língua de Sinais e aquisição da escrita. In: SILVA, I. R.; KAUCHAKJE, S.; GESUELI, Z. M. (Org.). Cidadania, surdez e linguagem. Desafios e realidades. São Paulo: Plexus, 2003. p. ? 147-159.

GOLDFELD, M. A Criança surda. Linguagem e cognição numa perspectiva sócio-interacionista. São Paulo: Plexus, 2001.

GUATTARI, F.; ROLNIK, S. Micropolítica: cartografias do desejo. 12. ed. Petrópolis: Vozes, 2013.

LACERDA, C. B. F.; ALBRES, N. A.; DRAGO, S. L. S. Política para uma educação bilíngue e inclusiva a alunos surdos no município de São Paulo. Educação e Pesquisa, São Paulo, v. 39, n. 1, p. 65-80, jan./mar. 2013.

LINS, H. A. M.; RICARTE, L. Em busca das agências infantis na cultura digital: o que as crianças nos apontariam? 2017. (No prelo).

LINS, H. A. M. Leitura, subjetividades e mídias: novas e velhas questões para a formação e atuação docentes. Nuances, Presidente Prudente, v. 28, p. 24-37, 2017.

LINS, H. A. M.; CABELLO, J. Desenvolvimento de objetos de aprendizagem ligados à alfabetização e ao letramento: o caso do Grupo de Estudos Surdos e Novas Tecnologias (Gestec). Linha Mestra, Campinas: Associação de Leitura do Brasil, v. VII, p. 85-96, 2013.

LEBEDEFF, T. B. Objetos de aprendizagem para o ensino de línguas: vídeos de curta-metragem e o ensino de Libras. Revista Brasileira de Linguistica Aplicada, Belo Horizonte, v. 14, n. 4, p. 1073-1094, 2014.

MARTINS, V. R. O.; LACERDA, C. B. F. Educação inclusiva bilíngue para surdos: problematizações acerca das políticas educacionais e linguísticas. Revista de Educação - PUC Campinas, Campinas, v. 21, n. 2, p. 163-178, 2016.

OLIVEIRA, M. O. Como "produzir clarões" nas pesquisas em educação? Revista de Educação Pública, Cuiabá, v. 24, n. 56, p. 443-454, maio/ago., 2015. Disponível em: <http://periodicoscientificos.ufmt.br/ojs/index.php/educacaopublica/article/view/2441>. Acesso em: 14 out. 2017. 
ROCHA, E. A. C.; LESSA, J. S.; BUSS-SIMAO, M. Pedagogia da Infância: interlocuções disciplinares na pesquisa em Educação. Da Investigação às Práticas, Lisboa, v. 6, n. 1, p. 31-49, mar. 2016. Disponível em: <http://www.scielo.mec.pt/scielo.php?script=sci_arttext\&pid=S2182$-13722016000100003 \& \operatorname{lng}=$ pt\&nrm=iso >. Acesso em: $15 \mathrm{dez} .2018$.

ROJO, R. Pedagogia dos multiletramentos. In: ROJO, R.; MOURA, E. (Org.). Multiletramentos na escola. São Paulo: Parábola, 2012. p. 11-31.

ROJO, R.; MOURA, E. (Org.). Multiletramentos na escola. São Paulo: Parábola, 2012.

SÁ, N. R. L. Questões a propósito de uma avaliação interativa na educação especial e na educação de surdos. Dialógica, Manaus, v. 1, p. 1-11, 1997.

SARMENTO, M. J. Gerações e alteridade: interrogações a partir da Sociologia da infância. $E d u$ cação e Sociedade, Campinas, v. 26, n. 91, p. 361-378, maio/ago. 2005. Disponível em: <http:// www.cedes.unicamp.br>. Acesso em: 5 jul. 2018.

STROBEL, K. L. As imagens do outro sobre a cultura surda. Florianópolis: UFSC, 2018. 